UDK $930.85(497.12 \mathrm{Mb}): 929$ Osterc

Manica Špendal Ljubljana

\section{SLAVKO OSTERC V MARIBORU}

Čeprav je le del svoje mladosti Slavko Osterc preživel v Mariboru, je duhovne stike $\mathrm{z}$ glasbenim dogajanjem $v$ njem prek svojih prijateljev, glasbenih kolegov in učencev ohranil do svoje smrti. $V$ Mariboru je prejel osnove glasbene izobrazbe na Državnem moškem učiteljišču, pri takratnima znanima glasbenima pedagogoma Hinku Druzoviču in skladatelju Emeriku Beranu. Zlasti Beran je Osterčevi glasbeni vzgoji posvetil veliko svojega prostega časa in ga spodbujal tudi $k$ samostojnemu komponiranju. V Mariboru je Osterc napisal (skoraj zagotovo) svoje prve skladbe. Mariborski poustvarjalci, zbori (Glasbena matica, Narodno-železničarsko društvo "Drava"), orkestri (Glasbena matica, Mariborska vojna muzika), in posamezni umetniki, so izvajali v Mariboru, na Ptuju, v Celju, v Beogradu, veliko njegovih zgodnjih del (iz timn. "amaterskega obdobja" do leta 1925 oziroma 1927). Prav njim gre zasluga, da se je Osterčevo ime že zgodaj in pogosto pojavljalo v takratnih slovenskih, jugoslovanskih in v Sloveniji izhajajočih nemških časnikih in je tako že s svojimi zgodnjimi skladbami vzbudil pozornost $v$ skladateljskih krogih, pa tudi širše glasbene javnosti. In končno, v Mariboru je Osterc spoznal nekaj spoštovanja vrednih prijateljev: kapelnika Ferda Herzoga in zlasti mariborskega notarja Ivana Ašiča, ki je postal Ostercu, kot je dejal Marijan Lipovšek, "drugi oče, prijatelj, podpornik in svetovalec. $V$ njegovem domu je Osterc našel svoj drugi dom in tja se je vselej zatekal". ${ }^{1}$ Ašič je bil tudi izvajalec Osterčevih samospevov, navdušen propagator njegovih skladb in mecen. $S$ finančno podporo je Ostercu omogočil študij v Pragi in vprašljivo je ali bi Osterc brez njegove pomoči mogel nadaljevati študij na praškem konservatoriju, ki je bil odločilnega pomena za njegov nadaljnji skladateljski razvoj. $^{2}$

Mariborsko Državno moško učiteljišče je Osterc obiskoval v letih 1910-14 (v šolskem letu 1910/11 pripravnico in do konca leta 1913/14 še štiri letnike učiteljišča). Iz ohranjenih vpisnic je mogoče povzeti, da je bil najboljše ocenjen iz predmeta violina, medtem ko je imel iz teorije in petja dobro in prav dobro, iz klavirja dobro in orgel prav dobro oceno. ${ }^{3}$ Vpisnice nam tudi povedo, da je Osterc vsako leto menjal

1 Lipovšek M., Osterc kot skladatelj, Slavko Osterc, Spominski zbornik, Murska Sobota 1963, 114.

2 Bratko Kreft je $v$ svojem spominskem zapisu o Ostercu navedel, da sta se I. Ašič in Osterc poznala še iz časov Maistrovih borcev (Spomin na Slavka Osterca in še marsikaj, Gledališki list Opere SNG Ljubljana 1979/80, št. 2, 25).

3 Vpisnice hrani Pokrajinski arhiv Maribor. 
bivališče: v šolskem letu 1910/11 je stanoval v Gasswerksstrasse 13 (v današnji Plinarniški ulici), leta 1911/12 v Burgergasse 2 ( $v$ današnji Mladinski ulici), $v$ letu 1912/13 v Mozartgasse 50 ( $v$ današnji Smetanovi ulici) in zadnje leto 1913/14 v Kärntnerstrasse 3 (na današnji Koroški cesti). Iz spominskega zapisa Osterčevega sošolca Janka Gačnika izhaja, da je Osterc v času šolanja na mariborskem učiteljišču sestavil dijaški orkester in vanj pritegnil nekaj svojih sošolcev, med drugimi poznejšega znanega mariborskega telovadnega pedagoga Pera Cestnika, Janka Gačnika, trgovca Martina Berdajsa idr. (osem do deset članov). Berdajs je omogočil mladim glasbenikom vaje $v$ prostorih mariborskega gradu, ki je bil takrat $v$ njegovi lasti. Osterc je vodil dijaški orkester in $v$ njem igral prvo violino. $V$ navedenem spominskem sestavku omenja Gačnik tudi, da je Osterc že kot dijak za svoj orkester komponiral nekaj skladb, vendar se te niso ohranile in tako zaenkrat ne moremo zanesljivo trditi, da je začel komponirati že $v$ času, ko je obiskoval mariborsko učiteljišče. V istem članku piše Gačnik, da je dijaški orkester na božični večer (1913) sodeloval pri polnočnici v cerkvi sv. Jožefa $\vee$ Studencih in pa, da je orkester pod Osterčevim vodstvom nastopil pri uprizoritvi ljudske igre Graničarji (v izvedbi dijakov učiteljišča). ${ }^{4}$ Tudi za štiriglasno mašo a cappela - hrani jo v prepisu Franja Kozarja NUK (glasbena zbirka) in bi jo Osterc utegnil leta 1913 ali 1914 komponirati za katero izmed mariborskih cerkev - avtorstvo še vedno ni dokazano.

Konec šolskega leta 1913/14 je Osterc sklenil šolanje na mariborskem učiteljišču in je bil s spričevalom, ki je datiran s 13. avgustom 1914, usposobljen za poučevanje na osnovnih šolah. 1. novembra je bil nastavljen kot učitelj v Sevnici ob Savi, a le do marca 1915, ko je bil vpoklican v vojsko. Po končani prvi vojni (odpuščen je bil 15. marca 1919), je najprej delal kot učitelj (od novembra 1919 do marca 1920) na osnovni šoli $\vee$ Krčevini $\vee$ Mariboru. Od tod je bil premeščen na osnovno šolo v Studencih pri Mariboru (od marca 1920 do oktobra 1920), nato pa je bil do konca leta 1921 spet nastavljen na krčevinski šoli.

8. maja 1920 je pred "Izpraševalno komisijo za obče ljudske in za meščanske šole" $v$ Mariboru opravil izpit in bil usposobljen za samostojno poučevanje na "občih ljudskih šolah" $v$ nemškem in slovenskem jeziku in še za "pomožno" poučevanje verouka "svoje izpovedi" na ljudskih šolah. 9. novembra 1920 pa si je z izpitom pred strokovno komisijo ( $v$ njej so bili Druzovič, Beran, dr. Perhavc in Marin) pridobil pravico še za poučevanje (v obeh jezikih) "petja in goslanja" na meščanskih šolah. ${ }^{5}$ $\mathrm{Na}$ zadnjem spričevalu je bil prvič vpisan kot Slavko Osterc, na vseh prejšnjih pa kot Alois in Alojzij. S 1. januarjem 1922 je Osterc nastopil službo strokovnega učitelja v Celju. ${ }^{6}$

Čeprav je Osterc v seznam svojih skladb uvrstil le tista dela, ki jih je bil komponiral od leta 1923 (za leto 1923 je navedel le Malo suito), ker se je bil svojim zgodnjim stvaritvam odrekel, pa je mogoče glede na ohranjene skladbe ( $v$ celoti ali $\checkmark$ fragmentih), nadalje na kritike in članke o izvedbah teh skladb $v$ slovenskih in nemških časnikih in glede na ohranjene izvirne koncertne sporede, sklepati, da je začel komponirati vsaj že leta 1920. Med prvimi skladbami, ki jih je napisal to leto (v

4 Gačnik J., Bil je odločen in samozavesten, Slavko Osterc, Spominski zbornik, Murska Sobota 1963, 67.

5 Spričevala hrani NUK (glasbena zbirka - mapa Osterc - Kronika).

$6 \mathrm{~S} 1$. januarjem je Osterc nastopil službo učitelja petja $v$ višjih razredih dekliške osnovne šole in petja, klavirja, violine ter telovadbe na deški in dekliški meščanski šoli v Celju. 
Veržeju ali Mariboru), sta bržkone dva mešana zbora s spremljavo godalnega tria, komponirana na Župančičevi pesmi Barčica in Na poljani. ${ }^{7}$ Iz leta 1920 verjetno datirajo tudi prvi trije samospevi Bolne rože, $\mathrm{Na}$ poljani in Zvezde žarijo, ki jih je Osterc izdal leta 1921 kot rokopis z naslovom "Tri pesmi Otona Župančiča" in so njegove prve natisnjene skladbe. $V$ mariborskem časniku Tabor je 18. maja 1921 bilo objavljeno: "Trije samospevi s spremljevanjem glasovirja. Naš mladi komponist Slavko Osterc je izdal v samozaložbi svoje prvence, ki pa odkrivajo talent in napovedujejo bodočega umetnika ..." ${ }^{8}$

Danes Osterčevih zgodnjih skladb (do leta 1923) večidel nihče ne omenja v razpravah. Ne upoštevajo pa jih tudi pisci člankov $v$ enciklopedijah in leksikonih, ker se jim je Osterc (kot že navedeno) odrekel, najbrž zato, meni Dragotin Cvetko, "ker so bile čisto romantične, oblikovane preprosto, izrazno še nedorečene", a "produkt vidno talentiranega, umsko in emotivno govornega samouka ..." Vendar pa je pomembno vedeti, na kakšen odmev so te skladbe naletele $v$ času nastanka in kako so jih sprejemali in vrednotili takratni glasbeniki. Sodeč po kritikah in kritiških poročilih v časnikih, ki so številčno naraščala v letu 1922, moremo ugotoviti, da so vsi glasbeni pisci - skoraj brez izjeme - občudovali Osterčevo izrazito nadarjenost, za samouka presenetljivo kompozicijsko znanje in veliko izrazno moč $v$ njegovih skladbah. Vsi pa so v njem že takrat videli modernista, kajti skoraj v vsaki skladbi jih je presenetil (kljub romantičnemu izražanju) s kakšno, do takrat v slovenski glasbi še neznano novostjo $v$ harmonskem stavku, melodiki ali instrumentaciji, pokazal pa je že zgodaj tudi nagnjenje do polifonskega oblikovanja. Zato menim, da je za celostno podobo skladatelja Osterca potrebno poznati tudi njegove zgodnje stvaritve (do leta 1923). V letu 1920 je Osterc (verjetno) komponiral prvo orkestrsko skladbo, simfonično sliko Krst pri Savici po znani Prešernovi pesnitvi, ${ }^{10}$ kajti že 12 . februarja 1921 jo je na Ptuju izvedla Mariborska vojna muzika pod vodstvom Ferda Herzoga. Simfonična slika Krst pri Savici je tako, po doslej preverjenih podatkih, prva koncertno izvedena Osterčeva skladba. ${ }^{11}$ Dne 22. aprila jo je Mariborska vojna mužika $z$ istim dirigentom nato še izvedla $v$ veliki dvorani hotela Union $v$ Celju na svečanem koncertu v korist gradnje tamkajšnje pravoslavne cerkve. Skladba Krst pri Savici je zasnovana programsko (Osterc ji je predložil program) ${ }^{12}$ in je "delana", kot je zapisal Ivan Ašič, "po vzorcu vodilnih motivov, kakor jih je uporabljal Wagner v operah". ${ }^{13}$ Gre za motive, ki jih je Osterc vnesel tudi v svojo prvo opero $z$ enakim naslovom. ${ }^{14}$ Komponiral jo je morda že leta 1920 v Mariboru, končal pa 9. avgusta 1921 v Veržeju, ${ }^{15}$ kar jasno kaže, da je nastala pred opero.

7 Obe zborovski skladbi sta ohranjeni $v$ rkp. v skladateljevi spominski sobi v Veržeju.

8 Tabor 1921 (18. maja), št. 110, 4.

9 Cvetko D., Osebnost skladatelja Slavka Osterca, Ljubljana 1993, 181

10 Partitura je v rkp. ohranjena v NUK (glasbena zbirka).

11 Ptujski list, Ptuj 1921 (6. februarja), III., št. 6, 2; Učiteljski tovariš (14. december 1922).

12 Program je naslednji: "Črtomirova posadka sliši od daleč signale Valjhunovih čet, ki se bližajo. (Rogovi in pozavne.) V pričakovanju napada darujejo pogani bogovom. (Rogi.) Kristjani napadejo in zmagajo. (Poln orkester.) Črtomir se reši k jezeru (flavta, harfa) in le spomin na Bogomilo ga veže še na življenje. (Vijoline, oboa.) S pomočjo ribiča se sestane Crtomir z Bogomilo, ki je pa medtem postala kristjana ter se odpovedala ljubezni. Mir oznanjajoči duhoven ublaži Črtomirove dvome in notranje boje ter ga spreobrne $v$ krsti. (Harfa, oboe, zvonček.) $S$ težkim srcem se odreče tudi on ljubezni, nakar se $z$ Bogomilo ločita za vedno." Po izvirnem koncertnem listu, ohranjenem v NUK (glasbena zbirka). 13 Jutro 1926 (7. maja), št. 103, 6.

14 Učiteljski tovariš 1992 (27. aprila), št. 17, 3.

15 Klav. izvl., kjer je zapisan datum, je ohranjen $v$ rkp. $\vee$ NUK (glasbena zbirka). Prva izvedba je bila 
Že s prvo orkestrsko skladbo je Osterc precej izzval takratne kritike. Skladbo so označili kot "povsem izvirno moderno muzikalno delo, čigar težišče leži v bujni žaroviti, mestoma bleščeči instrumentaciji po vzoru ruskih in francoskih modernistov". ${ }^{16}$ Leta 1921 ali 1922 je Osterc napisal še drugo simfonično sliko, za katero ga je inspirirala Levstikova balada Ubežni kralj, vendar se skladba ni ohranila; tudi k njej je priložil program, ${ }^{17} \mathrm{ki}$ ga moremo prebrati na ohranjenem fragmentu komentarja h koncertu, na katerem jo je 2. decembra 1922 v dvorani hotela Union v Celju izvedla Mariborska vojna muzika pod vodstvom kapelnika Josipa Majerja. Z Ubežnim kraljem je Osterc pritegnil še večjo pozornost glasbenih kritikov pa tudi skladatelja Rista Savina, ki je zapisal o Osterčevi skladbi med drugim, da ga "okrepuje melodika, simfonična širina razvoja in dobra instrumentacija ... Osterc bo še bolje pisal, a 'Ubežni kralj', njegovo mladeniško delo, iz kojeg izžareva samolastna milina, ostane vir onim, ki bodo nekoč iskali Osterca začetnika ..." ${ }^{18}$ Pisca kritiškega poročila o koncertu $\vee$ Cillier Zeitung je instrumentacija $v$ Ubežnem kralju še najbolj "spominjala na sijajno govorico Richarda Straussa ...", ${ }^{19}$ medtem ko je kritik v celjski Novi dobi zapisal, da je Osterc s tem delom "presenetil" poslušalce. "Pokazal se je, da je v resnici polnokrven muzik in mojster v instrumentaciji. Mislimo, da je tukaj njegovo polje, na katerem naj nadaljuje - programska glasba in opera", ${ }^{20}$ kar je bilo seveda zmotno mnenje, kajti prav do programske glasbe (svoja zgodnja orkestrska dela je zasnoval programsko, morda tudi pod vplivom prvega glasbenega učitelja Berana), je že čez nekaj let zazvel povsem nasprotno stališče, ko je večkrat govoril o "preživelosti orkestralnih slikanj in barv, Wagnerjanske dramatike in dramatičnih tremolov ..."12 "Ni čudno", je še leta 1928 zapisal, "ako današnji komponisti po večini ne navezujejo na romantike - tudi wagnerizem se je preživel temveč zidajo na temeljih, ki jih je postavil Bach". ${ }^{22} \mathrm{Z}$ izvedbami svojih oper Osterc ni žel vidnejšega uspeha. Avtor kritike $v$ Novi dobi je gotovo imel $v$ mislih prvo Osterčevo opero Krst pri Savici, ki jo je imelo namen uprizoriti Narodno gledališče $v$ Mariboru, vendar do izvedbe ni prišlo. Bržkone jo je umaknil s sporeda Osterc sam. V operi Krst pri Savici, h kateri sta libreto napisala skladatelj in mariborski pedagog Gustav Šilih, je Osterc sledil še v glavnem pozno-novoromantičnim zgledom in jo tudi označil kot glasbeno dramo v 3 dejanjih. $V$ njej je uporabil motive (kot že omenjeno) iz simfonične slike Krst pri Savici. Vendar pa v operi prevladujejo zaključene glasbene točke, arije, dueti, ansambli, večji poudarek pa je na pevskih glasovih. Tudi v operi je imel pozneje drugačne nazore: "Takoj po vojni je jela programska in ilustrativna glasba izgubljati tla ter se je zopet uveljavila absolutna glasba: absolutna

3.1.61 v Radiu Ljubljana.

16 Slovenski narod 1922 (29. aprila).

17 Program je naslednji: "Temna noč. Premagan kralj beži na konju po gozdu. Pred prepadom se konj vzpne ter ustavi. Kralj ne ve za vzrok, stopi raz konja in leže na plašč. Zaspi in sanja, da je on zmagovalec. Celi dvor se veseli z njim. Ujete sovražne čete mu defilirajo, premagan sovražni knez mu odda orožje ... Žena in hčerka mu prideta čestitat. - Da je premagan in se potika po gozdu, so bile pač le hude sanje. $V$ živih sanjah vstane ter hoče svojcem $v$ objem. Korak za korakom se približuje prepadu ter pade naposled vanj. Konj se splaši, poskoči ter pade istotako v prepad - Zopet noč." Po izvirnem koncertnem listu, ohranjenem $v$ NUK (glasbena zbirka).

18 Jutro 1922 (8. december), priloga, št. 290, 5.

19 Cillier Zeitung (14.12.1922).

20 Nova doba 1922 (15. december), št. 138, 3.

21 Bedina K., K vprašanju o kompozicijskih nazorih Slavka Osterca, Muzikološki zbornik 1968, IV, 116. 22 Ljubljanski zvon XVIII/1928, št. 3, 187. 
glasba brez forme je pa nemogoča in ni čuda, da so se začele spet pisati opere z zaključenimi točkami". Vendar pa je pripomnil, da imata "prednosti ta in ona smer". ${ }^{23}$

Prav evforični odziv je povzročila Osterčeva simfonija v C-duru Ideali, ki jo je praizvedel orkester mariborske Glasbene matice pod vodstvom Frana Topiča 3. novembra 1922 v mariborskem Narodnem gledališču. Že pol leta prej (maja 1922) so člani Mariborske vojne muzike (Vojaške godbe) simfonijo "preigrali" (tako se je izrazil F. Herzog, ki je ansambel vodil) "našim domačim merodajnim umetnikom in za to stroko zainteresiranim izvedencem (prof. Beran, Druzovič, Parma, prof. graškega konservatorija Paltauf, polkovnik Draškič in več drugih gospodov in dam). Kritika je enoglasna da je simfonija prvovrstna koncertna kompozicija in se brezdvomno lahko šteje med prve naše umotvore". ${ }^{24}$

Odzivnost na izvedbo simfonije je bila (kot omenjeno) izjemna, kakršne doslej zagotovo ni imela nobena slovenska skladba. O njej so poročali vsi obstoječi slovenski, oba ( $v$ Mariboru in Celju) izhajajoča nemška in še nekateri jugoslovanski časniki. Skoraj vsi kritiki pa so jo označili kot prvo slovensko simfonijo. Delo ima sicer po zapisu enega od njih "bodisi glede izdelovanja misli kakor tudi glede instrumentacije vse znake prvenca. $V$ splošnem pa je vtis, tega čisto programskega titularnega dela ugoden in zbudi tudi v poslušalcu to, kar je hotel doseči skladatelj prenese ga iz vsakdanje realnosti $v$ sfero idealov". ${ }^{25}$

Med Osterčevimi skladbami, ki so nastale od vključno leta 1922 pa do leta 1925 oziroma 1927 (do začetka njegovega "profesionalnega" obdobja), so v Mariboru izvedli (nekatera dela tudi praizvedli) še Serenado za visoki glas in orkester (na besedilo G. Šiliha, verjetno aprila 1924) s spremljavo klavirja, kar moramo povzeti po Beranovi kritiki, ki jo je napisal skupno $z$ oceno baleta $v$ treh epizodah $I z$ Satanovega dnevnika. ${ }^{26} \mathrm{~V}$ naslednjih letih pa še godalni kvartet $v$ a-molu $(1924),{ }^{27}$ dva samospeva (Mene ni požela kosa in Uspavanka - 1925). ${ }^{28}$

23 Ib., XLIX/1929, št. 6, 380.

24 Tabor 1922 (16. maja), št. 111, 3.

25 Tabor 1922 (3. november), št. 249, 3; kritiko o Osterčevi simfoniji je napisal tudi Oskar Dev, ki je med drugim menil "v nevenljivo zaslugo štejem orkestru, da je položil s svojim proizvajanjem temeljni kamen prvi slovenski simfoniji, ki bo imela svojo zgodovino ..." (Tabor, 10. novembra 1922, št. 246, 4); kot prvo slovensko simfonijo so Osterčevo simfonijo "Ideali" označili še številni pisci (Nova doba, 18. maja in 14. novembra 1922, Tabor 3. in 29. novembra 1922, Jutro 7. novembra in 8. decembra 1922 , Učiteljski tovariš 14. decembra 1922, Jugoslavija 19. maja 1922). Izvedbo Osterčeve simfonije so omenili še Slovenec (27. oktobra 1922), Marburger Zeitung (3. novembra 1922, št. 241, 3); partitura simfonije je $v$ rkp. ohranjena $v$ NUK (glasbena zbirka); koncertni list IV. koncerta mariborske GM je ohranjen med izvirnimi koncertnimi listi $\vee$ NUK (glasbena zbirka). Rkp. partiture simfonije, ki jo je Osterc končal 29.3.1922, hrani NUK (glasbena zbirka), Osterčev prepis partiture (brez partov) pa je $\checkmark$ arhivu SF.

26 Tabor 1924 (13. aprila), št. 86,4; Beranov članek je izšel tudi v prevodu v nemškem jeziku v Marburger Zeitung (12. aprila 1922); o obeh skladbah je poročal tudi ljubljanski Narodni dnevnik (15. aprila 1924), o baletu pa tudi zagrebški Zagreber Tagblatt (18. aprila 1924); obe skladbi sta ohranjeni v rkp. v NUK (glasbena zbirka), pri baletu partitura in klav. izvl. Serenada je nastala leta 1922, balet pa verjetno 1924.

27 Skladba je ohranjena $v$ rokopisu $\vee$ NUK (glasbena zbirka), nastala je leta 1923; kvartet $v$ a-molu je izvedel Godbeni kvartet (V. Bajde, Gregorinčič, Horvat in O. Bajde) na Umetniški akademiji 3. marca $1924 \vee$ Narodnem gledališču $\vee$ Mariboru (po lepaku, ohranjenem $\vee$ NUK - glasbena zbirka).

$28 \mathrm{Na}$ koncertu Narodno-železničarskega društva Drava sta samospeva izvedla tenorist Avgust Živko in pianistka Olga Hladky (po lepaku, ohranjenem v NUK - glasbena zbirka); rkp. obeh samospevov iz leta 1924 hrani NUK (glasbena zbirka), samospev Mene ni požela kosa (na besedilo A. Gradnika) je izšel v natisu v Slovenski glasbeni reviji 1952, I; samospev Uspavanka (verjetno Uspavančica), komponiran na besedilo Frana Žgurja, pa je natisnjen v zbirki Slavko Osterc, Samospevi, Ljubljana 1963. 
Poseben glasbeni dogodek je bil "Intimni" koncert Osterčevih skladb (obsegal je samospeve, klavirska in komorna dela) $v$ dvorani mariborskega učiteljišča (28. marca 1925). Na njem so ponovili spored s celjskega kompozicijskega koncerta Slavka Osterca z dne 2. marca 1925, z nekaj spremembami. Mariborskega koncerta so se udeležili najvidnejši nosilci državne in cerkvene oblasti. Uspeh prireditve je prispeval k odobritvi plačanega dopusta Ostercu za njegov študij v Pragi. ${ }^{29}$

Osterc pa je tudi po odhodu $\vee$ Prago in pozneje, med bivanjem $\vee$ Ljubljani, bil stalno "prisoten" v Mariboru, bodisi osebno ali s svojimi skladbami. Teh sicer po letu 1925 niso več $v$ tolikšnem številu vključevali $v$ sporede. 7. maja 1926 je orkester mariborske Glasbene matice krstno izvedel Osterčevo simfonično sliko Povodni mož (po Prešernovi baladi). ${ }^{30}$ 11. marca 1929 je bila $v$ mariborskem Narodnem gledališču predstava operne enodejanke (skeča) Iz komične opere, v izvedbi ljubljanskega opernega ansambla. ${ }^{31}$ Prav tako $v$ Narodnem gledališču je 11. marca 1941 nastopil Ljubljanski trio z Osterčevo skladbo Trio pour violon, violoncelle et piano, ki je bilo njegovo zadnje izvedeno delo $v$ Mariboru pred drugo svetovno vojno. ${ }^{32}$ Do obeh navedenih izvedb je prišlo po zaslugi Osterčevih najzvestejših prijateljev, I. Ašiča (predstava operne enodejanke $\mathrm{lz}$ komične opere), medtem ko se je za "Trio" zavzel Osterčev učenec Karol Pahor, s katerim si je Osterc $v$ tridesetih letih redno dopisoval in od leta 1932-35 vodil z njim predkompozicijsko "dopisno šolo". Pahor je Osterca tudi najbolj natanko poučil o glasbenem dogajanju v Mariboru. ${ }^{33}$ Osterc pa je tudi poslej občasno prihajal $v$ Maribor in tako do konca življenja (kot že uvodoma povedano) ohranil stik $z$ mestom, v katerem se je kot skladatelj najprej uveljavil.

Ugotovitev, ki jo lahko ob sklepu sestavka zapišem je, da je bil Osterc v Mariboru do leta 1925/26 najbolj pogosto izvajan slovenski skladatelj. To velja tudi za čas, ko je delal v Celju, kajti večidel njegovih skladb so tudi tu izvedli mariborski poustvarjalci. Tako bi lahko skorajda govorili o "Osterčevem obdobju" v slovenski glasbi (od 1920 do 1926) na Štajerskem.

Menim tudi, da bi morali bolj slediti zgledom sosednjih, kulturno bolj osveščenih dežel, ki ob pomembnejših obletnicah svojih skladateljev, skušajo te počastiti tako, da predstavljajo v natisu in z izvedbami kar največ njihovih stvaritev, tudi manj znanih ali sploh še neizvedenih. Tudi Slavko Osterc bi si to zaslužil.

$29 \mathrm{Na}$ koncertu so nastopili tenorist Ašič, pianistka Apihova, godalni kvartet (Vidmajer, Fink, Osterc, Wohrlowizs) in Mariborska vojna muzika pod vodstvom kapelnika Herzoga. Spored mariborskega koncerta je obsegal v prvem delu Impresije za klavir (Spominski list, Hrepenenje, Valse, Pustni ples), samospeve (Usta so mi bila nema, Uspavančica, En bretana Cicifuj, Mene ni požela kosa) in iz liričnega kvarteta (Nocturno, Humoreska, Serenada), v drugem delu pa Sonatino za klavir, samospeve Belokranjske uspavanke in Humoresko ter Scherzo za orkester (po izvirnem koncertnem listu, ohranjenem $v$ NUK - glasbena zbirka). $V$ kritiki koncerta $v$ mariborskem časniku pa je zapisano, da je Mariborska vojna muzika izvedla Idilo in Erotikon iz orkestrske skladbe Bagatele (Tabor, 12. aprila 1925). O Osterčevem koncertu v Mariboru so poročali tudi v drugih časnikih (Slovenec 15. aprila 1925, Jutro 1. aprila 1925, Nova doba 2. aprila 1925, Marburger Zeitung 31. marca 1925).

30 Jutro 1926 (7. maja), št. 103, 6; rkp. iz leta 1924 hrani NUK (glasbena zbirka).

31 Večernik 1929, št. 2, 2.

32 Večernik (7. in 20 marca 1941); koncert so priredili pod naslovom Večer jugoslovanskih glasbenih avtorjev (UJMA), izvajalci pa so bili F. Ornikova (violina), Č. Šedelbauer (violončelo), M. Lipovšek (klavir). Rkp. skladbe iz leta 1939 hrani NUK (glasbena zbirka).

33 Cvetko D., Fragment glasbene moderne. Iz pisem Slavku Ostercu, Ljubljana 1988. 
Although Slavko Osterc spent only a part of his youth in Maribor he kept up with the musical development there through his friends, musical colleagues and pupils until death. In Maribor he received the basis of musical instruction at the teachers' training college from H. Druzovič and E. Beran. In Maribor Osterc (almost certainly) started to compose. Maribor reproductive musicians (orchestras, choruses, individuals) were performing in Maribor, on Ptuj, at Celje and in Belgrade a great many of his early works from the so-called 'amateur' creative period (from 1920 to 1925, or to 1927 resp.). It is thanks to them that Osterc's name was already at an early time and frequently mentioned in Slovene, Yugoslav, and in Slovenia issued German, newspapers. In Maribor Osterc had several respectable friends, thus the bandmaster F. Herzog and the notary I. Ašič. Especially the latter was also Osterc's adviser, supporter, as well as performer of his lieder. By extending financial support he made it possible for Osterc to continue his studies in Prague, which was of decisive significance for Osterc's further development as a composer. Today Osterc's early works (those written up to 1923) remain almost unmentioned because he renounced them. Judging by the response they had been met with by the reviewers at that time they should, however, be made known again if we are to arrive at a complete picture of Osterc as a composer.

Osterc was in Maribor (up to the 1925-26 season) undoubtedly the most often performed composer. This is true also of the period when he was active at Celje, as many of his compositions were here as well played by Maribor artists. In this way we can perhaps speak of 'Osterc's period' in the Slovene music (from 1922 to 1926) in Štajersko (Styria). 